\title{
The Re-Scheme Project for the Mexican Cartography Plan
}

\author{
Cecilia Z. Cortina G. ${ }^{a^{*}}$, Leonardo Tun Humbert ${ }^{a}$, Shachak Pe'eri ${ }^{b}$ \\ a Secretaría de Marina (SEMAR) Veracruz-México \\ ${ }^{b}$ Office of Coast Survey, National Oceanic and Atmospheric Administration (NOAA), Silver Spring, MD, USA \\ *cecilia.cortina@gmail.com
}

Keywords: Nautical chart, re-scheme

\begin{abstract}
:
The Mexican Navy is empowered by its current federal legislation to produce charts over military and civilian ports within Mexico.

To fulfil this task, a National Nautical Cartography Program has been developed. The program currently consists on a production and maintenance scheme of 254 nautical charts at scale within general, coastal, approach, harbour and berthing usage bands. The design of the National Nautical Cartography Program is the result of port infrastructure and maritime traffic analysis that also follows the International Hydrographic Organization (IHO) recommendations published in the "Regulations for International (INT) Charts and Chart Specifications of the IHO" S-4. This paper will present details on the re-scheme project that includes Electronic Navigation Chart (ENC) cell footprints and their compilation scales in order to produce a seamless chart coverage along the coastlines of Mexico and a more efficient production workflow. The re-scheme project intends to provide more detail to existing charts and also provide current updates to ever-changing port infrastructure of the country and the emergence of new navigation routes for commerce and tourism.
\end{abstract}

Additional benefits of the re-scheme project include:

Providing an orderly design of ENC cell for program management, standardizing progressive scales with chart display, and establishing better international collaboration between Mexico and its neighbours on charts along the borders and INT charts. 